\title{
CONSECUENCIAS DEL DECRETO DE CONVERSIÓN AL CRISTIANISMO DE 1502 EN LA ALJAMA MORA DE VALLADOLID
}

\author{
Manuel Moratinos García
}

Olatz Villanueva Zubizarreta

Una de las fuentes más reveladoras para conocer a la comunidad morisca vallisoletana ha sido y es, a nuestro juicio, la renovación del censo enfitéutico de $1538^{1}$; un documento que da cuenta detallada de los vecinos propietarios de casas o solares en el barrio de Santa María o antigua morería, especificando el titular, oficio, propiedad y su localización deslindada.

Ocupados en desgranar la valiosa información que arrojaban sus más de quinientos folios y despreocupados de cualquier otra consideración que no fuera la de enjuiciar su calidad de documento histórico, no habíamos caído en la cuenta de preguntarnos sobre su razón de ser. Desde que en 1414 se fijaran los términos para el disfrute del solar de la morería entre el cabildo de la Iglesia Mayor de Santa M aría -como propietario del suelo- y sus futuros inquilinos, desconocíamos si la renovación del censo se llevaba a cabo con regularidad o si éste de 1538 respondía a algo extraordinario.

Ahora, tras la consulta de un pleito hallado en la Chancillería de Valladolid ${ }^{2}$, sabemos que se trata efectivamente de un hecho extraordinario que obedece a un conflicto surgido entre arrendador y arrendatarios de la aljama, a resultas de la Pragmática de 1502 que obligaba a los moros del reino de Castilla al bautismo. Como veremos a lo largo de estas páginas, el pleito se inicia como consecuencia de este decreto y sus repercusiones tendrán enfrentadas a ambas partes durante más de tres décadas, en las cuales se presentarán pruebas y testimonios que enriquecen notablemente nuestro conocimiento sobre los moriscos vallisoletanos.

\footnotetext{
1. Archivo Histórico Provincial de Valladolid, Protocolos, legaj o 13; un documento consultado ya y publicada su información -aunque no íntegramente- por GóMEZ RENAU (1993).

2. Archivo de la Real Chancillería de Valladolid, Pleitos Civiles n. ${ }^{\circ}$ 2, ZARANDONA Y BALBOA, C-159-1. La existencia de este documento nos fue dada a conocer por Miguel Ángel de Benito, a quien queremos desde estas líneas hacer público nuestro más sincero agradecimiento.
} 


\section{ORÍGENES DE LA ALJAMA DE VALLADOLID}

La vecindad de mudéjares en Valladolid se rastrea desde, al menos, mediados del siglo XII y a lo largo de toda la Edad Media, aunque su discreta aportación escrita a la vida económica -al no encontrarse entre los may ores contribuy entes de la hacienda pública- y social -al no contar entre sus filas a miembros destacados de la colectividad urbana-, ha hecho que hay an pasado desapercibidos en las crónicas. Por su parte, el registro arqueológico ha contribuido en los últimos años a ap ortar más luz sobre su existencia, dándonos a conocer, por ejemplo, las manifestaciones materiales de su maqbara (Balado et alii, 1991; Marcos et alii, 1991) o de algunas de sus actividades artesanales, como la alfarería (Villanueva, 1998), que evidencian su reconocimiento y participación en el colectivo humano de la ciudad.

El decreto dictado por la reina Catalina de Lancaster en $1412^{3}$ que establecía la obligatoriedad de recluir a estas minorías en un barrio propio hizo que sus integrantes, que hasta esa fecha habían vivido dispersos por la villa, fueran a establecer su residencia en la proy ectada morería. Para ello, las instituciones municipales acordaron reservar un suelo propiedad del cabildo eclesial para su arrendamiento y disfrute.

El lugar elegido, situado al sur de la aglomeración e intramuros, era un solar que el cabildo había conseguido a través de la donación y venta, respectivamente, de dos medias huertas entre los años 1341 y 1345. Primeramente, fue Teresa Sánchez, viuda de Juan Pérez de la cal de Francos, quien el 25 de may o de 1341 donó a esa institución una media huerta, con su mitad de un pozo y una noria, que había heredado de su hijo, Juan Pérez. Más tarde, García Pérez que había comprado la otra mitad de la propiedad a Teresa Pérez, mujer de Juan Pérez y nuera de Teresa Sánchez, la vende el 22 de junio de 1345 al cabildo por la cantidad de 1.600 maravedíes.

La información sobre las condiciones del arrendamiento de la morería se recoge en un documento conservado en el Archivo de la Catedral de Valladolid ${ }^{4}$, en el que se recogen también

3. La ley había sido promulgada en las Cortes de Valladolid del año 1405, aunque fue publicada el 2 de enero de 1412 por la reina. En lo que a la separación física de estas comunidades se refiere, la orden dictaba que todos los judíos, moros y moras del reino vivan separados de los cristianos en lugar retirado de las ciudades y villas donde habiten, formando un barrio aparte que había de estar circunvalado por una cerca o muralla y en ésta debía de haber una sola puerta para el servicio (GÓMEz RENAU, 1993: 45).

4. Archivo de la Catedral de Valladolid, legajo III, $\mathrm{n}^{\circ} 43$. El documento no es otro que, curiosamente, la “ ejecutoria a pedimento del prior y cabildo de la Iglesia Mayor de esta villa de Valladolid en el pleito que trató con los vecinos del barrio de Santa María” y que recoge asimismo, a lo largo de sus cincuenta y dos folios, el proceso que nos ocupa. Igualmente queremos agradecer a Jonás Castro su amabilidad a la hora de facilitarnos la consulta de dicho documento. 
los dos escritos anteriores y que incluye una carta de poder que los moros hacen a favor de sus cuatro representantes con fecha del 11 de diciembre de 1413, que dice:

Sepan cuantos esta carta de poder vieren como nos, el aljama e los hombres buenos moros de ella, de la morería de aquí de Valladolid, convienen a saber Hamet Alfaquí, Braen Ronda, Maestre Aly Ojos de Enamorado, Mahomat Pynacho, Ramiro hermano del Allcalde, Mahomat Gordo, Muça Conde, Hebraen hijo de doña Odylen, Hebrahen Conde, Aly Guidado, Adolea nieto de Ostyn, Brahen Xedel, Aly hermano de Buenaño, Mahomat hijo de Brahen el viejo, Aly Sancho, Aloçenen hijo de Maestre By, Ali Morahen, Maestre Hamet de Madrit, Ramiro sobrino del Alcalde, Aodalla Conde, don Aly Allcalde, Maestre Mahoma talcafeus, Haray hijo del viejo e otros moros asaz de la dicha morería e aljama, los cuales éramos muchos de las dos partes de los moros que éramos e somos en la dicha aljama e morería, estando dentro en la dicha morería de esta dicha villa, ayuntados en la casa de oración, llamados todos los moros de la dicha aljama e morería por Seymenia Candelera, mujer que fue de Montejo moro, según que la dicha hizo fe que los llamara a todos para el negocio ayuso a cuanto e según lo habemos por costumbre. Otorgamos e conocemos por esta carta que damos e otorgamos todo nuestro poder cumplido, por nos e por todos los moros y moras de la dicha morería y aljama de la dicha villa de Valladolid que ahora son e por los que serán e fueren cabo adelante para siempre jamás, a Hamet Alfaquí e a Farax Buenaño e a Aly Allcalde e Aly Ojos de Enamorado, moros vecinos de Valladolid, a todos cuatro en uno e a los tres e a los dos apartadamente para que, por nosotros todos y cada uno de nos los que ahora somos de la dicha morería e aljama así moros como moras e por los que fueren e serán aquí en delante de la dicha morería e aljama de Valladolid por siempre jamás, para que puedan hacer e hagan con los señores prior y cabildo de la Iglesia de Santa María la Mayor de esta dicha villa, compusición e avenencia o renta o arrendamiento o contrato o enfeteosym o cualquier otro perpetuo contrato siibanuon censsii o en otra guisa so condición o condiciones, modo o modos, o simplemente e de la guisa que a ellos plugiere que por bien tuvieren.

\section{A continuación, el texto especifica que el poder se realiza para que sus rep resentantes actúen} ante el cabildo en el contrato de arrendamiento ${ }^{5}$ de:

(...) una huerta con su noria e casas y corrales que están en ella, que es de los dichos señores, del dicho cabildo, en la cual dicha huerta e casas e corrales ahora de presente los moros e moras de la dicha morería e aljama de Valladolid moran e están, que es cerca la Puerta del Campo, deslindada so ciertos linderos a toda avenencia o compusición o renta, en cualquier manera que los dichos nuestros procuradores o algunos de ellos en nuestro nombre e de la dicha aljama con los dichos señores prior e cabildo hicieren e trataren. Nos y cada uno de nos lo prometemos de haber e lo hemos e habremos por rato e por firme e valedero para ahora e para siempre jamás, para lo cual todos e cada uno de ellos cumplir e guardarlo que los dichos nuestros

5. A.C.V., legajo III, n. ${ }^{\circ} 43$, fols. 9v-16r. 
procuradores hicieren e trataren e arrendaren y otorgaren con los dichos señores del cabildo, en razón (...) un suelo de huerta con su anoria e con sus casas e corrales en que solía morar el hortelano que era a la sazón en la dicha huerta que vos los dichos señores prior e cabildo por razón de la dicha vuestra iglesia habedes, dentro en esta dicha villa, cerca de la puerta que llaman del Campo, de la cual dicha huerta e casas e corrales son linderos de la una parte el corral de Olleros, e de la otra parte casas de la cofradía de Santiago e casas del dicho cabildo e casas del prior de San Juan e otras casas assaz contra la cerca e de la otra parte la calle pública, el cual dicho suelo de la dicha huerta e casas e corral e anoria arrendamos e tomamos enfeteosyn subanno a censun según dicho es de vos, los dichos señores e prior e cabildo, con todas sus entradas e con todas sus salidas e con todos sus derechos e con todas sus pertenencias e con todas las mejorías que en la dicha huerta son hechas e se hicieren de aquí adelante, cuantas hoy día han e deben haber así de hecho de derecho, desde el cielo hasta la tierra e desde la tierra hasta los abismos, desde hoy día que esta carta es hecha para siempre jamás, para que la tenga la dicha aljama e sus herederos que sean moros o moras tan solamente, e no cristianos ni judíos ni otros algunos salvo moros e moras como dicho es por precio e cuantía de cuarenta florines de buen oro e de buen peso del cuño de Aragón en cada un año para siempre jamás.

El cual dicho suelo de la dicha huerta con su anoria e casas e corral arrendamos e tomamos de vos, los dichos prior e cabildo en enfeteosyn en a censu, según suso es declarado e en esta guisa que se sigue, que los moros e moras de la aljama (...) que puedan hacer e mandar hacer en el dicho suelo de la dicha huerta, edificar moradas, casas, anorias, pozos e otras casas (...) e otrosi (...) que puedan vender e anajenar e trocar e cambiar, dar o donar, e anajenar los edificios de casas o casa (...). Otrosi que vos, los dichos señores prior e cabildo, los que ahora sodes e fuesen de aquí adelante que seades tenidos e obligados de guardar e defender e ampara la dicha aljama e moros e moras de ella (...). Es nuestra voluntad que por razón e fuerza de este contrato no puedan ser traspasados los dichos edificios e huerta e casas si no a moros o maras como dicho es (...). De vos pagar los dichos cuarenta florines puestos en paz y en salvo aquí en Valladolid, en vuestro poder o de vuestro cierto mandado, cada unaño para siempre jamás, la mitad de los dichos florines por el día de Navidad e la otra mitad de los dichos florines el día de San Juan de junio, sopena que vos peche la dicha aljama moros e moras de ella así los que ahora son como los que fuesen de aquí adelante, cuatro florines por cada un día de cuantos días pasasen por pena e por postura e por nombre de interés (...) Para lo cual todo e cada parte de ello, así a tener e guardar e cumplir según dicho es en esta carta de obligación e renta e arrendamiento de enfeteosyn según dicho es (...) fecha e otorgada en Valladolid, miércoles tres días del mes de enero del año del Nacimiento de Nuestro Salvador Jesucristo de mil cuatrocientos e catorce años.

De su lectura se desprende que los miembros de la aljama habitan ya a finales de 1413 en el lugar elegido para el establecimiento de la morería y que los términos del contrato perpetuo de arrendamiento del sitio se firman, no obstante, unos días más tarde, concretamente el 3 de enero de 1414. Podríamos deducir de ello que, de alguna manera, un acuerdo inicial entre ambas partes pudo facilitar el traslado de los miembros de la aljama a este lugar, dejando -suponemos, según esto- para poco tiempo después la redacción del escrito que fijara los términos del acuerdo. 


\section{LA PRAGM ÁTICA DE 1502: ORIGEN DE UN PLEITO ENTRE EL CABILDO Y LOS MORADORES DEL BARRIO DE SANTA MARÍA DE VALLADOLID}

Como se sabe, el 11 de febrero de 1502 se dictó la Pragmática que daba a elegir a los musulmanes del Reino de Castilla entre el bautismo a la fe católica y el exilio, aunque seis días más tarde se les prohibiera abandonar el territorio, anulándose la posibilidad de la partida (Ladero, 1969: documentos $n .^{\circ} 148$ y 149). La orden general obligaba por lo tanto a los moriscos a abandonar sus creencias religiosas y sus convenidas instituciones, así como a un cambio de nombre acorde a su nueva situación jurídica.

La sentencia debió hacerse efectiva con cierta celeridad -como más tarde veremos, en el mes de abril de ese mismo año-, siendo así y en lo que al patronímico en particular se refiere, que un año después, en un alarde celebrado en Valladolid (Álvarez y Carreras, 1998), los integrantes de las cuadrillas a las que pertenecerían los moradores del barrio (cualquiera de las tres del Mercado) aparecen todos con nombre “castellanizado”; así, por ejemplo, sabemos que Mahomat Alcalde pasó a llamarse Bernaldo de León, Brayme Ali, Jerónimo alcaller o M agoma Andado, García López Andado.

También, en fecha relativamente inmediata, tuvo lugar el desmantelamiento de edificios de la morería tales como el almají y la casa de bodas, elementos íntimamente relacionados con sus prácticas religiosas. El cabildo de la Iglesia May or de Santa María -como propietario del solar de la morería, además de como veedor de la religiosidad local- entendía así que la conversión al catolicismo traía consigo el abandono y la negación de toda manifestación religiosa anterior. Pero además, y más importante, consideraba finalizado en consecuencia el arrendamiento del terreno de su propiedad que constituía el barrio -que a partir de esta fecha pasó a denominarse de Santa María en lugar de morería- al perder sus moradores la condición de moriscos y al no estar obligados desde entonces a vivir apartadamente.

Pues bien, la amenaza de hacer efectivo el desalojo del barrio por parte del cabildo, por un lado, y la expropiación de tan emblemáticos edificios, por otro, hizo que ambas partes iniciaran un contencioso. Los moriscos vallisoletanos exigían, por su parte, responsabilidades sobre las actuaciones acometidas y se rebelaban ante las medidas anunciadas. Mientras, el cabildo insistía en su legitimidad para actuar como lo había hecho y en poner fin al contrato de arrendamiento que había firmado hacía casi cien años.

Así las cosas y ante la falta de consenso mutuo, se optó por trasladar la contienda a la Audiencia de la Chancillería a la espera de que un fallo judicial pusiera fin al conflicto. El pleito en cuestión (recogido en el documento mencionado) se sucedió entre los años 1505 y 1537, durante los cuales se narran hechos y se presentan innumerables pruebas y testimonios que enriquecen, además, nuestro conocimiento sobre esta comunidad castellana.

El proceso arranca el 12 de diciembre de 1505, fecha en la que el prior y el cabildo de la Iglesia May or de Valladolid toman procuradores para iniciar el pleito contra los moradores del 
barrio de Santa María, nombrando como principal a Sancho de Paternina ${ }^{6}$. Por su lado, el 8 de agosto de 1506, la otra parte da poder cumplido a Juan de Benavides, Diego de Buenaño y Juan de la Rua, para que en nombre de todos los vecinos puedan pleitear contra la iglesia ante la Real Chancillería.

El día 28 de ese mismo mes, comienza el turno de exposición de los hechos de mano de Juan de Benavides, explicando ante la Audiencia cómo se levantó la aljama de moros en las dos medias huertas sitas junto a la Puerta del Camp o hace noventa y dos años pagando cuarenta florines de oro anuales y cómo ahora el cabildo quiere que se le devuelva la propiedad con todo lo edificado en ella. El 13 de septiembre es nuevamente el procurador de los moradores del barrio, Juan López de Valladolid, quien ratifica lo anteriormente expuesto y añade e incide en que ciertas posesiones de sus interesados habían sido derribadas, entre ellas el almají, la casa de bodas y, particularmente, una serie de viviendas anexas a aquéllas, como las de unos herradores y la del alcaller Diego de Rojas, entre otras.

Al día siguiente, Sancho de Paternina inicia el turno de presentación de pruebas adjuntando los documentos de la cesión y compra de las dos medias huertas sobre las que se proy ectó la morería y el contrato de arrendamiento de la misma. Además de éstos, el dicho Paternina presenta un padrón de los moradores del barrio de ese mismo año de 1506, en el que se mencionan a ciento noventa y cuatro vecinos, que imaginamos se corresponden con los titulares de prop iedades (ver listado al final del texto).

Por su parte, el 15 de septiembre, es decir, un día después, el procurador de los moradores del barrio presenta como prueba a su favor ante los oidores de la institución una carta de los Reyes Católicos enviada desde Sevilla a la aljama de Valladolid. De su lectura se desprende que se encuentran al corriente del conflicto y que instan a las autoridades eclesiásticas y civiles de la ciudad a que no les obliguen a los moros a abandonar sus moradas. La cédula dice así:

El Rey y la Reina

(a la) Aljama, alfaquíes, alguacil, viejos buenos hombres moros de la villa de Valladolid.

Nos somos informados que vosotros o alguno de vos tenéis buena voluntad de vos convertir a nuestra santa fe católica, de lo cual habemos habido mucho placer porque deseamos la salvación de vuestras ánimas y pues a nuestro Señor plugo que los moros del reino de Granada que eran en tanta cantidad como sabéise nacidos e criados e envejecidos en aquel yerro e más apartados de la conversación de los cristianos, se convirtiesen a nuestra santa fe católica. Deseamos que así lo hagáis vosotros pues habéis tenido tanta continua conversación de los cristianos e vos es más cercano el conocimiento de nuestra fe católica. Por ende nos vos rogamos que queráis poner en obra de vos convertir, certificando vos que allende del servicio que en ello haréis a nuestro Señor y bien y provecho a vuestras ánimas, nos haréis mucho placer e haciéndolo

6. El texto de la Ejecutoria, por su parte, se inicia con una carta de los reyes Carlos y doña Juana, en la que se adelantan las razones del conflicto a tratar y en la que se especifica que se comenzó por nueva demanda ante los dichos nuestro presidente e oidores. 
así vos mandaremos honrar e mirar por vosotros e por las cosas que os tocaren de muy buena voluntad. E porque asimismo habemos sabido que dilatáis la dicha conversión a causa devuestras casas que tenéis a censo de la iglesia colegial e del abad de Valladolid, diciendo que está puesta condición que si os tornáredes cristianos vuelvan las dichas casas a la dicha iglesia, nos escribimos al abad, prior y canónigos e cabildo de la dicha iglesia que si tal condición hay la den luego por ninguna e asimismo al corregidor de esa misma villa que solicite ser ciertos que se hará así y que por aquella condición no seréis sacados de vuestras casas e que las ternéis con hasta aquí las teníades. De la ciudad de Sevilla a seis días del mes de febrero de mil quinientos dos años, yo el rey, yo la reina.

La fecha de la carta resulta cuando menos un tanto sorpresiva pues, además de ser unos días anterior a la de la propia Pragmática -hecho de por sí chocante-, evidencia que la voluntad del cabildo a desalojar a sus arrendatarios del solar de la morería se remonta, incluso, a fechas en las que el decreto de conversión debía de ser un simple vaticinio. A este respecto, existen otros documentos que manifiestan asimismo el temor a la Pragmática desde décadas atrás y el aparente deterioro de las relaciones de convivencia de la minoría mudéjar en la sociedad castellana; no en vano, ya el 3 de diciembre de 1493 los rey es se vieron obligados a divulgar una carta en la que se prohibía manifestar en su reino la opinión de que la Corona proyectara la expulsión de los mudéjares castellanos ${ }^{7}$. Sea como fuere, en concreto, la carta escrita a los responsables de la iglesia vallisoletana demuestra que las intenciones del cabildo al respecto y la consiguiente preocupación de la aljama vallisoletana ante dicha medida llevaban fraguándose desde tiempo atrás y que ello pudo motivar que los perjudicados se dirigieran a los monarcas para que intercedieran a su favor 0 , por lo menos, estuvieran al corriente de lo que ellos consideraban un agravio.

Pero retomando el proceso judicial que nos ocupa, el 12 de octubre de 1506 el procurador Sancho de Paternina se querella con los rep resentantes de los moradores del barrio, en concreto con Alonso de Cuéllar, herrero, Francisco Gallardo, también herrero, y Leonor Gómez, mujer de Alonso Gómez. En su primera comparecencia alega, además, que en 1414 el cabildo había dado a renta las dos medias huertas sitas junto a la Puerta del Campo de la Verdad a los moros para que éstos

7. La carta, dirigida a las distintas autoridades municipales, decía: Sepades que por parte de las aljamas de los moros de todas las çibdades y villas y logares de los nuestros reynos e señorios nos es fecha relaçion por su petiçion diçiendo que de pocos dias a esta parte algunas personas a fyn de escandalizar los pueblos contra ellos andan diziendo y dibulgando y echando fama que nos queremos mandar a los dichos moros que salgan fuera de nuestros reynos, a cabsa de lo qual diz que no entienden en sus heredades, ni hallan en que trabajar para su sustentamiento ni quieren contratar con ellos personas algunas ni tienen de ellos aquella confiança que tenian de antes que la dicha fama se dibulgase (...), e porque nuestra merçed e voluntad no fue ni es de mandar salir los dichos moros fuera de los dichos nuestros reynos nos mandamos dar esta nuestra carta en la dicha razon (LADERO, 1969: documento n. ${ }^{\circ}$ 62). 
hicieran allí su aljama y por las que se pagaban anualmente 40 florines de oro, pero ahora que la aljama ha desaparecido p or la conversión de sus moradores al cristianismo, cree legítimo que el cabildo reclame que le sean reintegradas esas antiguas huertas arrendadas.

El 16 de octubre, la Audiencia de la Chancillería decide abrir un plazo para que ambas partes litigantes presenten nuevas pruebas y anuncia que desde esa instancia se iniciará un turno de preguntas que tendrán que ser respondidas bajo juramento por testigos de ambas partes. Así, el 11 de noviembre, se cita a los testigos del cabildo -los canónigos Juan de Torquemada, provisor, Rodrigo de Ampudia y Sancho de Natos- para que respondan a una serie de nueve preguntas en representación de su parte, formuladas p or el procurador del barrio, Hernán López de Valladolid. Con la primera quiere saber si el prior y cabildo conocen a los vecinos del barrio y las propiedades que éstos ocupan. La segunda nos revela un dato de interés que ya adelantábamos, como es la fecha de conversión de los miembros de la aljama vallisoletana, al ser preguntados si sabían que ésta había tenido lugar por el mes de abril de 1502. La tercera les pregunta si conocían que al tiempo de la conversión, la reina había enviado una carta a las autoridades eclesiásticas pidiéndoles, rogándoles e encargándoles que por se tornar cristianos los dichos vecinos del dicho barrio, que no les tomasen sus casas e que se las dejasen como antes las había. La cuarta pide que ratificaran si era cierto que a dicha carta, tanto el corregidor de la villa, el doct or de Villafranca, como los dichos prior y cabildo, habían respondido que acataban los deseos allí manifestados por la soberana. La quinta y la sexta aluden ambas a si se ha seguido recibiendo de parte de los moradores de Santa María la renta anual de los cuarenta florines durante los últimos cuatro años y medio, es decir, después de su conversión. La séptima plantea si el prior y cabildo poseen la casa que solía ser mezquita e almají con sus corrales e casas de bodas e carnecerías y da la impresión de que parece ser así pues en la siguiente pregunta se consulta si consideran que las dichas casas que así tienen y poseen en el dicho barrio podrían rentar ocho mil maravedíes anuales. Y la novena y última pide que informen si esas propiedades se encuentran dentro de los límites de la huerta que se dio a censo a la aljama.

A continuación, el 20 de enero de 1507, los vecinos de Santa María dan todo su poder cumplido a Juan de Benavides, Pero López de Buenaño, Beltrán de Abanades, Pedro Andado, Diego de Ulloa, Rodrigo Ginete, Francisco Mejorado, Juan de Figueroa, Juan de San Martín, Juan Díaz Carretón y Francisco Andado, para que acudan como representantes a responder a las preguntas de la Audiencia. Precisamente, el día 14 del mes siguiente serán llamados Juan de Benavides, Pero López de Buenaño, Francisco Andado, Rodrigo Ginete, Diego de Ulloa, Juan de Figueroa, Beltrán de Abanades y Francisco Mejorado a declarar sobre ocho nuevas preguntas efectuadas por el procurador del cabildo, que son: la primera, si conocen al prior y cabildo de la Iglesia Mayor y a los moradores del barrio de Santa María que solía ser morería; la segunda, si conocían el sitio donde estaba edificada la dicha morería, ahora barrio de Santa María; la tercera, si sabían, vieron u oy eron que el dicho sitio era y es de la Iglesia May or de Valladolid desde tiempo inmemorial y que hasta que se edificó era una huerta muy grande con sus casas y otros edificios; la cuarta, si sabían que en 1414 se edificó la huerta como morería merced a un arrendamiento 
enfitéut ico exclusivo a moros y moras, y que si no fuese así se devolviese todo el sitio con lo edificado a la Iglesia Mayor; la quinta, si saben que las condiciones se cumplieron hasta la conversión al cristianismo de sus moradores y si hoyno viven moros, ni hay aljama ni tan siquiera nombre de aljama; la sexta, si saben que las personas presentadas en el memorial coinciden con aquéllas que tienen las casas en la antigua aljama y que no quieren restituirlas al cabildo, en cuyo caso que declaren las propiedades que cada uno de ellos tiene; la séptima, que digan cuántos maravedíes podría rentar cada casa anualmente; y la octava, que manifiesten su conformidad pública con su declaración.

Finalizado este turno de preguntas, el 26 de abril de 1507 la Audiencia abre un nuevo plazo para que ambas partes puedan seguir ap ortando nuevas pruebas referentes al litigio e inicia el 3 de julio una nueva ronda de preguntas -doce esta vez- con los testigos de los moradores del barrio de Santa María, en esta ocasión: Lope de Buenaño, alcaller, Luis de Melen (?), carpintero, Juan de Figueroa, carpintero, Diego de Medina, carpintero, Bernardino de Madrid, borceguilero, Francisco del Castillo, carpintero, Juan de Vega, vecino de Valladolid, Francisco Catalán, alcaller, Francisco de Benavides, alcaller y Gerónimo, también alcaller. El formulario -preguntado por el procurador de los vecinos del barrio- vuelve a retomar en las cinco primeras preguntas las mismas cuestiones que habían marcado la primera tanda, insistiendo nuevamente en asp ectos relacionados con el origen y las condiciones del arriendo de la morería. La sexta retoma la pregunta antes formulada a los canónigos y que revelaba un dato inédito, al ser preguntados si sabían que la conversión había tenido lugar por el mes de abril de 1502. La séptima resulta igualmente interesante pues se les consulta si era cierto que antes de su conversión el cabildo les había instado a no hacerlo por temor a perder sus casas y que ellos habían prometido no hacerlo y seguir como estaban. La octava iba dirigida a que confirmaran si efectivamente, incluso después de la conversión, los moradores del barrio habían seguido pagando la renta de los cuarenta florines, hasta hace un año cuando empezó el pleito. La novena les pregunta si saben que el prior y cabildo han tomado las casas y corrales que solían ser almají, con otras casas en que hacían sus bodas y otros dos pares de casas en que viven los herederos de Pero Alvarez Conde y Diego de Rojas, alcalleres, e otras casas en que vive Mari Fernández y otras casas que fueron de Beatriz Barbuda. La décima, además, se pregunta si calculan que la renta de estas propiedades tomadas puede llegar a alcanzar los ocho mil maravedíes y, la undécima, si conocían que al tiempo queellos se convertían, los reyes habían enviado una carta al corregidor para que la hiciera llegar al cabildo y éste a los vecinos del barrio. Finalmente, la duodécima solicitaba la confirmación de todo lo respondido, de pública voz y forma.

Seguidamente, el 18 de noviembre de ese mismo año de 1507, la Audiencia de la Chancillería establece un nuevo plazo de presentación de pruebas y testimonios.

Casi veinte años después, durante los cuales no tenemos constancia de ningún otro hecho relacionado con la causa, el 20 de julio de 1526 el procurador del prior y cabildo hace traslado al tribunal de una carta de posesión a favor de la iglesia sobre el almají, casa debodas y carnicería del barrio fechada el 31 de agosto 1506. Según se dice en ella y con esa fecha, en presencia del 
lugarteniente de merino Bernaldino de Ayala y del escribano público Juan Sánchez de Santiesteban, el bachiller Juan de Cáceres, canónigo de la iglesia colegial de Santa María, requerió con esta carta ejecutoria del rey e de la reina nuestros señores a dicho Bernaldino de Ayala lugarteniente de merino e le pidió e requirió que la guardase e cumpliese según e como en ella se contiene e en guardándola e cumpliéndola dijo que le pedía e pidió que posiese a los dichos sus partes e a él en su nombre en la posesión de las dichas mezquita e casa de bodas e casa de carnecería que es en la dicha morería e suelos de ella e así puestos en la dicha posesión que los defendise e amparase en ella. E luego el dicho señor teniente de merino tomó la dicha carta ejecutoria de sus altezas en sus manos e leyola e púsola sobre su cabeza e dijo que la obedecía e obedeció e dijo que estaba presto de la cumplir según e como en ella se contiene e cumpliéndola tomó por la mano al dicho bachiller Juan de Cáceres canónigo por los dichos señores prior e cabildo en su nombre e metiole dentro de la dicha mezquita e casas de bodas e dijo que le ponía e puso en la posesión de ellas e dijo de parte de sus altezas dende ahora le defendía e amparaba en la dicha posesión e luego el dicho canónigo Juan de Cáceres echó fuera de toda la dicha mezquita e casa de bodas a todas las personas que dentro estaban e anduvo por ellas de una parte para otra e tomó la llave de la mezquita e cerrola de su mano. Se trata, por lo tanto, de un documento que muestra que otra sentencia había dictado a favor del cabildo colegial sobre la posesión de dichos edificios, que luego derribaría.

Por fin, el 12 de octubre de 1526 el tribunal resuelve a favor de los moradores del barrio de Santa María en el recurso interpuesto contra ellos por el prior y cabildo eclesiásticos. La sentencia obliga a éste a devolver la casa de mezquita e bodas y, por lo que se refiere a las viviendas, legitima a sus moradores a seguir viviendo en ellas.

Como cabría sup oner, la parte perdedora no acata de buen grado el fallo e intenta de alguna manera seguir en su empeño de conseguir, cuando menos, otro tipo de beneficios de sus arrendatarios, una vez que éstos habían alcanzado de la justicia real su permanencia en el barrio. Así, el 20 de octubre de ese mismo año, su procurador Sancho de Paternina se da por enterado de la sentencia, aunque insiste en que su postura es la cierta, dado que en la carta de arrendamiento de 1414 se especificaba que éste era para la aljama y estando ahora disuelta, considera que el contrato no tendría que tener validez. Además, expresa su temor a que los moradores del barrio, al actuar a partir de entonces como particulares, hagan más difícil al cabildo el cobro de la renta de los cuarenta florines, puesto que el contrato se hizo con el colectivo de moros y si quisieran a partir de ahora podrían negarse a hacerlo, más si cabe cuando habían sido dados por labris por el presidente y los oidores de la Chancillería. En consecuencia, solicita que se redacte un nuevo contrato de arrendamiento particular a cada morador y que se revoque el antiguo que atendía al colectivo.

Al día siguiente, el nuevo procurador de los moradores del barrio, Antón de Oro, acaso animado por el fallo anterior a favor de sus representados, envía a la Audiencia un escrito por el que reclama al cabildo los daños causados en el edificio del almají y casa de bodas -en especial, 
la sustracción de su madera para ser p osteriormente vendida- y las otras casas que estaban adosadas a aquéllas. Se indica, al respecto, que los muros de dichos edificios fueron derribados y sustraídas su piedra y su teja, además de la madera que, esp ecifica, era muy buena e muy bien labrada $e$ pintada ricamente, estimando el valor de esta última en unos cuatrocientos ducados. Finalmente, solicita que les sea devuelta la madera y, curiosamente, que se cree un censo para todas las casas del barrio, cuestión esta última en la que los moradores parecen estar de acuerdo con el cabildo.

El 20 de noviembre de 1526, la Audiencia de la Chancillería abre un nuevo plazo de alegaciones referentes a ambas cuestiones, es decir, a cómo se deberían de pagar los dichos censos, dado que ambas partes coinciden en que se hagan, y a la restitución del almají y casa de bodas, tal y como reclaman los vecinos de Santa María.

Así, el 18 de enero de 1527, se abre un turno de doce preguntas dirigidas a los testigos de los moradores del barrio, cuyo representante es ahora Diego de Buenaño; éstos son, Bartolomé de Valladolid, portero de la Puerta del Campo, Juan Rodríguez, alcaller, Francisco Cisneros, alcaller, Cristóbal Hernández, alcaller, Pedro de Madrid, espadero, Gómez de Villalón, Juan de Valladolid, mercader, Alonso de Paredes, trompeta, Rodrigo, cochero, Luis Hurtado, calderero, Juan Serrano, carpintero, Juan López Enamorado, carpintero, Pedro de ?, armero, M aestre Miguel, Pedro de Alcalá, sastre, Alonso del Castillo, carpintero, Francisco de Rojas, escribano, y Bartolomé de Medina. Las cuatro primeras preguntas vuelven a retomar cuestiones referentes al origen, límites y condiciones de arriendo de la antigua aljama. La quinta hace referencia a los edificios derruidos, dándonos información, para ser confirmada, de que efectivamente entre lo edificado en el barrio estaban la mezquita que decían almají e otras casas donde hacían todos ellos las bodas e otra casa en que moraba el alfaquí e otras que tenían para cocina e otro circuito a manera de patio en que había dos corredores grandes de más de noventa pies de cada uno e otras casas de pobres, lo cual todo como dicho es estaba labrado y edificado en el dicho circuito y en el dicho suelo. La sexta afirma que cuando los moros se convirtieron, los edificios ahora derruidos estaban en perfectas condiciones y ricamente labrados y pregunta a los encuestados si están de acuerdo en que su reconstrucción no podría hacerse con doscientos cincuenta mil maravedíes pero sí con trescientos mil. La séptima p ide que recuerden si, ya convertidos, el prior y el cabildo, además de otras personas a las que éstos instigaron, se dirigieron al barrio a llevarse la madera y el resto de los materiales de dichos edificios derribados. La octava insiste en que si corroboran que el valor de esos materiales, incluidas puertas y ventanas, superaría los cien mil maravedíes una vez vendidos. La novena se refiere a si conocían que el cabildo había arrendado, además, esos solares durante más de diez años por cerca de seis mil maravedíes anuales, mientras que la décima, si asimismo sabían que las otras dos pares de casas, que ahora las han traspasado a Francisco Chapinero (la que fuera de Pero Alvarez Conde) y a Luis de la Serna (la de Beatriz la Barbuda), estaban y a incluidas en la renta de los cuarenta florines. Y la undécima insiste en la misma cuestión, es decir, que ratifiquen que durante más de veinte años el prior y cabildo había 
estado cobrando, además de la renta de los cuarenta florines, las cantidades correspondientes al alquiler de esas propiedades cuando se encontraban incluidas lógicamente en el censo global.

Finalmente, la duodécima solicita la confirmación pública del testimonio manifestado.

A finales de ese mismo año, el 31 de diciembre, el interrogatorio -de siete preguntas- de dirige a los testigos que presenta el procurador Sancho de Paternina, con lo cual la Audiencia da por terminado el plazo de presentación y exposición de pruebas.

En contra del cabildo, dictamina que debe de pagar a los moradores del barrio una cantidad de dinero ${ }^{8}$ por la madera sustraída de la mezquita y casa de bodas. Por contra, obliga a los vecinos de Santa María a que formalicen con su dueño un censo individual por cada uno de los suelos y casas, aunque, siguiendo las pautas establecidas en el antiguo censo de fundación de la aljama, sin exceder de la renta global de los cuarenta florines de oro anuales.

El día 10, la Audiencia abre un nuevo plazo de alegaciones para que ambas partes litigantes presenten toda la documentación concerniente a cómo consideran que se tienen que escriturar los nuevos contratos de arrendamiento. Para ello, durante esos dos meses de julio y agosto se llevan a cabo sendos interrogatorios de tres preguntas, que darán por finalizado el periodo establecido para las alegaciones y dejarán visto para sentencia el juicio.

Por fin, el 20 de julio de 1537 el presidente y los oidores de la Real Audiencia dictaminan el fallo correspondiente a la causa en curso. Por lo que se refiere a la petición formulada por el prior y cabildo de redactar un nuevo contrato individual a los vecinos del barrio, las autoridades acuerdan que mandamos que los contratos que los dichos vecinos del dicho barrio de Santa María han de hacer conforme a la dicha nuestra sentencia, sean contratos infiteoticos e que se obligue cada un vecino particularmente por la parte que tienen o tuvieren e haga contrato infiteotico en forma en el que se obligue a todas las casas que de natura del dicho contrato vieren e se comprendan a que cada e cuando que quisieren enajenar alguna de las dichas casas si requerido el dicho prior $e$ cabildo no la quisiere por el tanto (...) lleve el dicho prior e cabildo la cincuentena parte del precio porque así se vendiere la dicha casa. Además, a propósito de las casas que se encontraban próximas al almají, que se habían visto afectadas por el derribo, expresan que condenamos a los dichos prior y cabildo a que dejen e restituyan las dichas casas a los vecinos del dicho barrio de Santa María para que ellos las tengan e posean conforme e como las otras casas del dicho barrio de Santa María e hagan el contrato al dicho prior y cabildo de las dichas casas de la misma manera que dicho es de las otras casas del dicho barrio de Santa María.

8. El texto especifica, aunque nosotros no entendamos exactamente su significado, que los vecinos del barrio reciban en cuenta de la dicha madera todo lo que pareciere haber gastado los dichos prior y cabildo en seguimiento del pleito que trataron con doña Mencia de Ayala, mujer que fue de Antonio de Fonseca sobre las dichas casas de mezquita e bodas. Al respecto, desconocemos la identidad de estas personas, así como su relación con esas propiedades y la naturaleza del pleito al que se alude. 
Por último, en lo referente a la demanda que los moradores hicieran por la madera sustraída del almají, se dicta que condenamos al dicho prior y cabildo que páguense a los vecinos del dicho barrio de Santa María toda la madera que habían llevado de la casa de la mezquita e de la casa de las bodas e que los vecinos del dicho barrio recibiesen en cuenta de esto todo lo que el dicho cabildo había gastado en el pleito que había tratado con doña Mencia de Ayala e los herederos del licenciado Pedrosa sobre las dichas (roto); mandamos que se recompense los gastos que el dicho cabildo hizo en el dicho pleito, con lo que podía valer la dicha (roto) e los daños que el dicho prior y cabildo hizo en las dichas casas de manera que las dichas partes sobre esto de la dicha madera e daños e (roto) dicho pleito no se puedan ni demandar más los unos a los otros ni los otros a los otros. E damos por libres e quietos a entre ambas partes de todo ello e no hacemos condenación de costas.

Con todo, nueve días después, el procurador de los moradores del barrio de Santa María vuelve a dirigirse a la Audiencia, solicitando, por un lado, que sus representados pudiesen vender sus casas sin tener que pagar al cabildo la cincuentena que establecía la sentencia e indicando, por otro, que el valor de los materiales sustraídos del almají y casa de bodas (madera, tejas y piedra) ascendería a doscientos mil maravedíes.

Sin embargo, con este último alegato finaliza el pleito o, mejor dicho, la documentación recogida en el legajo, ignorando, p or lo tanto, si sus consideraciones fueron tenidas en cuenta o no. Lo que sí queda claro definitivamente es que este fallo judicial fue el detonante del censo de 1538.

\section{EL CENSO DE LOS VECINOS DEL BARRIO DE SANTA MARÍA DE 1538}

Como adelantábamos al inicio del trabajo y unas líneas más arriba, una de las consecuencias directas del pleito que había mantenido en litigio durante las últimas décadas a los representantes de la iglesia colegial de Valladolid y a los vecinos del barrio de Santa María, es la redacción del censo enfitéutico de 1538, el contrato individual de cada propiedad del dicho barrio, tal y como la Audiencia de la Chancillería había fallado que se llevara a cabo. El documento que engloba cada uno de estos nuevos contratos particulares lo escritura el escribano de la Iglesia Mayor Cristóbal de Montesinos.

No cabe duda de que este censo se presenta como un documento excepcional para conocer a la comunidad morisca vallisoletana, en la medida en que nos da cuenta uno a uno a sus habitantes, especificando además su oficio, y la situación de su propiedad con sus linderos (ver listado al final del texto).

Parece así que el barrio poseía, al menos, unos ciento cincuenta y cuatro suelos -en su may oría edificados- y una única entrada cuando era morería desde la calle del Mercado. Sus calles principales, paralelas a ésa, eran las de Carpintería, de Carnicería o Caminería (luego denominada 
Arcallería $^{9}$ y la de la Ronda, a las que cruzaban la calleja de Buenaño, la de Barriga, la de Carrión, la del almají y la calle del Corrillo. Como establecimientos públicos, amén de los ya mencionados mezquita y casa de bodas, el barrio contaba con tres mesones ${ }^{10}$ : el del Arco, situado en la calle del Corrillo, el de la Rua en la calle Carpintería y el del Tresillo, en la trasera de la calle Carnicería, además de una carnicería “donde se pesaba la carne del dicho barrio en tiempos que era aljama”, colindante con la antigua mezquita y regentada en esa fecha por la viuda del alcaller Lope del Trigo ${ }^{11}$.

Las ciento cincuenta y cuatro propiedades registradas estaban en manos de ciento veinticuatro titulares. La may oría (noventa y seis, es decir, un 78\%) p oseía una única casa, mientras que veintiún personas (el 16\%) tenían dos, seis (el 5\%) tres y una única, el carpintero Sancho de Mendoza, cinco. A partir de ello se podría estimar -aplicando un coeficiente 4- que la población del barrio rondaría los quinientos o seiscientos vecinos.

El documento permite además conocer las actividades profesionales desempeñadas por la comunidad, entre las que destacaban p or su número la carpintería y la alfarería ${ }^{12}$. Con independencia de que una quinta parte de los propietarios que renuevan el censo no especifican su oficio, del total, cincuenta y uno eran carp interos (un 40\%) y veinte alcalleres (16\%), seguidos en menor número por y eseros y esparteros (ocho en cada caso, es decir, el 6,4\%), dos herradores, dos borceguileros, un calderero, un zapatero, un taladrero, un guarda del camp o, un broquelero, un carretero, un tundidor y una comadre. Se observa además cómo existe una tradición familiar en cuanto al desempeño de una actividad laboral concreta se refiere; así, por ejemplo, los miembros de las familias Andado, Bazán, Retaco o Giguñuela parecen dedicarse en su may oría a la carpintería o los Alcalde, Ramírez, Benavides y Trigo, a la alcallería. Asimismo, se constata una especia de agrupación espacial de las personas que comparten profesión en una misma calle o zona del barrio: los carpinteros, en su may oría, en la calle del mismo nombre o los alcalleres en torno a la calle de la carnicería.

9. El documento que certifica la venta de unas casas por la viuda del alcaller Melchor de Alba en 1560, aclara que están “ en la calle que antiguamente se llamaba calle de la carnecería y agora se llama la calle de la arcallería ... fronteras de los suelos que solia ser el almaxy” (A.H.P.V., P rotocolos, legajo 315, fols. 406r-417v).

10. A.H.P.V., Protocolos, legajo 13, fols. 203, 83 y 246, respectivamente.

11. A.H.P.V., Protocolos, legajo 13, fol. 262.

12. Un reciente estudio sobre los alcalleres moriscos del barrio se pres entó en el VII Congrès International sur la Céramique Médiévale en Méditerranée celebrado en Tesalónica entre los días 11y16 de octubre de 1999 (Moratinos Y VillanUeVa, e.p.). 


\section{SOBRE LA TRAZA Y EL EMPLAZAM IENTO DEL ALMAJÍ Y DE LA CASA DE BODAS DE LA ANTIGUA MORERÍA VALLISOLETANA}

Como hemos visto a lo largo de este pleito, la apropiación y posterior derribo de la mezquita y casa de bodas del barrio por parte del cabildo de la iglesia de Santa María supuso un verdadero ultraje para sus moradores, convirtiéndose en uno de los objetivos de sus reivindicaciones.

Algunos datos aportados por el documento de la Chancillería, así como otros provenientes de otras fuentes de información, tales como algunas notariales o la cartografía antigua, nos brindan la oportunidad de adelantar ciertos apuntes sobre su traza y de proponer una hipótesis sobre su localización en el barrio.

Suponemos que la construcción de estos edificios en la huerta arrendada al cabildo a principios del siglo $\mathrm{XV}$, se debió de llevar a cabo a la par que se levantaban las casas de los vecinos o, incluso, con cierta preferencia. Cuando menos, en las postrimerías de 1413 existe una casa de oración donde, para esa ocasión, los moros se reúnen llamados por Seymena Candelera para otorgar una carta de poder a los represent antes que actuarán como testigos en la firma del contrato de arrendamiento de la morería. Suponemos también que el emplazamiento de esta construcción coincide con el del almají y casa de bodas de principios del siglo XVI, cuy o solar -una vez derruidos dichos edificios- sigue estando presente en la memoria colectiva de los moriscos. La documentación consultada revela, además, que en torno a estas casas se concentraban otras de disfrute público, como la carnicería y la casa del alfaquí.

Las declaraciones de algunos de los testigos llamados a resp onder en los interrogatorios del pleito a preguntas concretas sobre este asunto, ofrecen información excepcional sobre dichos edificios. De hecho, uno de los enunciados de las preguntas de 1527 arroja ya en sí mismo datos sustanciales acerca de las construcciones derribadas, que no son otras que la mezquita que decían almají e otras casas donde hacían todos ellos las bodas e otra casa en que moraba el alfaquí e otras que tenían para cocina, e otro circuito a manera de patio en que había dos corredores grandes de más de noventa pies de cada uno e otras casas de pobres. En sus respuestas, todos los testigos coinciden en que se trataba de edificios de grandes dimensiones y ricamente labrados; inclusive, parece que habían seguido decorándose hasta fechas muy recientes puesto que uno de los testigos, el carpintero Juan López Enamorado, reconoció haber trabajado allí en varias ocasiones.

Pero, sin duda, el testimonio más revelador es el del escribano de cuarenta y dos años Francisco de Rojas, en cuy a declaración se recoge que el almají, además de estar muy bien labrado de yeso, estaba decorado con azulejos a la morisca, pero también y más importante que:

Tenían en el circuito del dicho barrio una casa grande que llamaban almají donde este testigo vio muchas veces siendo muchacho que hacían oración los dichos moros del dicho barrio, e otra casa junto a ella, todo dentro de un circuito, donde hacían las bodas de entre ellos con su cocina e aparejos de que tenían 
necesidad, bien grande e ampliadamente; porque este testigo como dicho viene, estuvo muchas veces en las dichas bodas con otras personas de esta villa que lo iban a ver e los vio hacer sus oraciones de moros e hacer sus bodas. E vio que estaba el dicho almají como a manera de vergel con unos álamos u olmos altos y un pozo grande donde se lavaban los dichos moros para hacer la oración. Y en el dicho almají había una sala grande con sus corredores en que se ponían mujeres y unos corredores grandes cerrados y largos y dentro otras casillas donde vio a algunos moriscos extranjeros y de ellos decían que eran pobres. Y después de esto vio este testigo que siendo cristianos los dichos moros, los dichos edificios estaban enteros e vivía dentro Luis de Aranda, procurador ${ }^{13}$; y que se acuerda que eran los dichos edificios gran circuito detrás e llegaban hasta la ronda de la cerca e hasta la calle que atraviesa hasta la Puerta del Campo.

Pero como hemos sabido, desgraciadamente estas construcciones fueron derribadas a instancias del prior y cabildo de la iglesia de Santa María. Ello debió de tener lugar -aunque no dispongamos de testimonios escritos explícitos- en la primera quincena del mes de septiembre de 1506, puesto que el 31 de agosto, cuando los representantes de la iglesia toman posesión del almají, casas de bodas e carnecería, se encuentran en pie y el 13 de septiembre, el procurador de los moradores del barrio incluye por vez primera en su demanda su queja por el desmantelamiento de éstos y otras viviendas anexas. Tras su derribo, como hemos visto, los materiales de construcción fueron además sustraídos y vendidos por el cabildo; a propósito, algunos testigos narran, como el alcaller Cristóbal Hernández, que vieron que de parte del dicho prior y cabildo, recogían $e$ cobraban la madera un clérigo, que no sabe su nombre, e lo hacía llevar en carretas e andaba pesquisando qué personas eran a cargo de la dicha madera e despojo e aún sobre ello hizo prender a algunos de los vecinos del dicho barrio e los vio presos este testigo, otro (el carpintero Juan Serrano) detalla que se trataba de madera, despojo, puertas e ventanas e teja, lo que se llevaban en las carretas.

Desde entonces, las emblemáticas edificaciones estaban arruinadas y asílo certifican en 1525 otros carpinteros que asisten como testigos ante el interés del alcaller Pedro Fernández por arrendarlo, atestiguando con tal ocasión que el recinto estaba hecho muladar y que sólo conservaba algunas paredes p ero no su armadura ${ }^{14}$. Pese a su estado, su arriendo siguió interesando a los vecinos durante los años venideros e, incluso, en 1611 -a propósito de la expulsión- se sigue rememorando su suelo como el que albergaba "lo que solía ser mezquita"15.

13. Otro testigo, el alcaller Juan Rodríguez, dijo que al tiempo que los dichos moros se tornaron cristianos (...) se acuerda que estando la corte en esta villa, estaba un caballero en las dichas casas del dicho alfaquí y en los dichos dos corredores.

14. A.H.P.V., Protocolos, legajo 5, fols. 276r-285v.

15. A.H.P.V., Protocolos, legajo 1.503, fols. 148r-149v. 1611, 11 octubre. 
A lo largo del siglo XVI, las múltip les referencias que aluden directa o indirectamente al lugar del almají permiten asimismo conjeturar acerca de la ubicación ap roximada del mismo dentro del barrio. Distintos indicios -los deslindes de las casas del censo de 1538, determinados documentos notariales e, incluso, el plano de 1738 elaborado por Ventura Seco- apuntan a que la manzana en cuestión estaba ubicada entre la calle de la Carnicería y la calle de la Ronda, que a un lado había casas (en su mayoría, de alcallería) y al otro, una calleja a la que llamaban del almají. Sabiendo como sabemos que dicho espacio se mantuvo como solar, al menos, durante prácticamente todo el siglo XVI, es curioso advertir cómo el lugar que creemos que fue el de su emplazamiento, en el plano de 1738 ap arece y ermo. ¿Será que, incluso mucho tiempo después de abandonar los moriscos el barrio, tal emblemático suelo siguió rememorando su solemne pasado y permaneció sin edificar? Acaso sea una casualidad, pero todo induce a considerar que ése fue el solar en el que se levantó el almají y el resto de los edificios que conformaban el complejo religioso de los moriscos vallisoletanos (ver plano al final del texto).

Pocos días después de concluir la redacción de este trabajo, se publicó en la prensa local (Norte de Castilla, jueves 11 de noviembre de 1999) un artículo que anunciaba el descubrimiento de restos humanos en el solar en obras del hasta ahora Hospital Militar, situado en el Paseo de Zorrilla de esta ciudad, que albergará el Centro Regional de Hemoterapia y Hemodonación, dependiente de la Consejería de Sanidad y Bienestar Social de la Junta de Castilla y León. Se trata, como lo desvelan la documentación y las crónicas locales (sobradamente publicadas), del suelo donde primeramente estuvo el osario de los moros y más tarde -desde 1563- el convento de Nuestra Señora del Carmen de carmelitas descalzos. Los restos descubiertos (una veintena de individuos, seis de ellos de corta edad) corresponderían, por lo tanto, a cualquiera de estas dos etapas, pero, como declaraba el Director General de Salud Pública en ese mismo artículo de prensa, “más trabas para el desarrollo de la obra hubiera supuesto el encontrar restos arqueológicos”. Si efectivamente eran inhumaciones de los moriscos vallisoletanos, nos tememos que la desidia de la Administración regional ha destruido la oportunidad única de documentarlas, ¿tendremos que dar con los restos de Almanzor para considerarlos arqueológicos?

\section{BIBLIOGRAFÍA}

Álvarez Bezos, S. y Carreras Zalama, A.: Valladolid en época de los Reyes Católicos según el alarde de 1503. Universidad de Valladolid, serie Historia y Sociedad n. ${ }^{\circ} 62$. Valladolid, 1998.

Balado Pachón, A.; Escribano Velasco, C.; Herrán Martínez, J.I. y Santamaría GonZÁLEZ, J.E.: “La Maqbara de Valladolid. Un interesante cementerio mudéjar”. Revista 
de Arqueología, n. ${ }^{\circ}$ 127, noviembre, (1991), pp. 38-45.

Gómez Renau, M.: Comunidades marginadas en Valladolid. Mudéjares y moriscos (s. XV-XVI). Diputación Provincial de Valladolid. Valladolid, 1993.

Ladero Quesada, M.A.: Los mudéjares de Castilla en tiempos de Isabel I. Instituto "Isabel la Católica” de Historia Eclesiástica. Valladolid, 1969.

Marcos Villán, M.A.; PAlomino LÁZARo, A.L y Hoy As Díez, J.L.: “Excavaciones arqueológicas en la Casa de la Beneficencia de Valladolid (calle Chancillería, $\mathrm{n}^{0} 12,13$ y 14)”. Arqueología Urbana en Valladolid. Junta de Castilla y León, Consejería de Cultura y Bienestar Social. Valladolid, 1991, pp. 215-229.

Moratinos Gargía, M. y Villanueva Zubizarreta, O.: "Los alcalleres moriscos vecinos de Valladolid”. VII e Congrès International sur la Céramique Médievale en Méditerranée (Thessaloniki, 11-16 octubre de 1999), en prensa.

Villanueva Zubizarreta. O.: Actividad alfarera en el Valladolid bajomedieval. Studia Archaeologica 89. Universidad de Valladolid. Valladolid, 1998.

\section{RESUMEN}

La morería vallisoletana estuvo ubicada desde 1412 en un solar arrendado a censo perpetuo por el cabildo de la iglesia colegial de Santa María. En 1502, como consecuencia del decreto de conversión al cristianismo, el propietario del suelo entiende que la pérdida de la condición morisca de sus arrendatarios anula aquel contrato y ello da lugar a un conflicto entre ambas partes que será llevado a la Audiencia de la Chancillería. La reveladora información recogida en el sumario de la causa ofrece datos inéditos acerca de los miembros de esta comunidad, así como de las características del barrio donde moraban.

\section{ABSTRACT}

Since 1412 the Moorish quarter of Valladolid was situated in a site leased in perpetuity by Santa María’s Chapter. In 1502, as a result of a Conversion Act to Christianity, the ground owner came to the conclusion that the loss of the Moslem condition by the tenants repeals that contract. This interpretation caused a dispute between both parties wich will be taken to the Chancilleria Audience Chamber. The revealing information gathered in the summary offers unpublished facts about the members of the Moorish community, as well as about the characteristics of the quarter in wich they lived. 


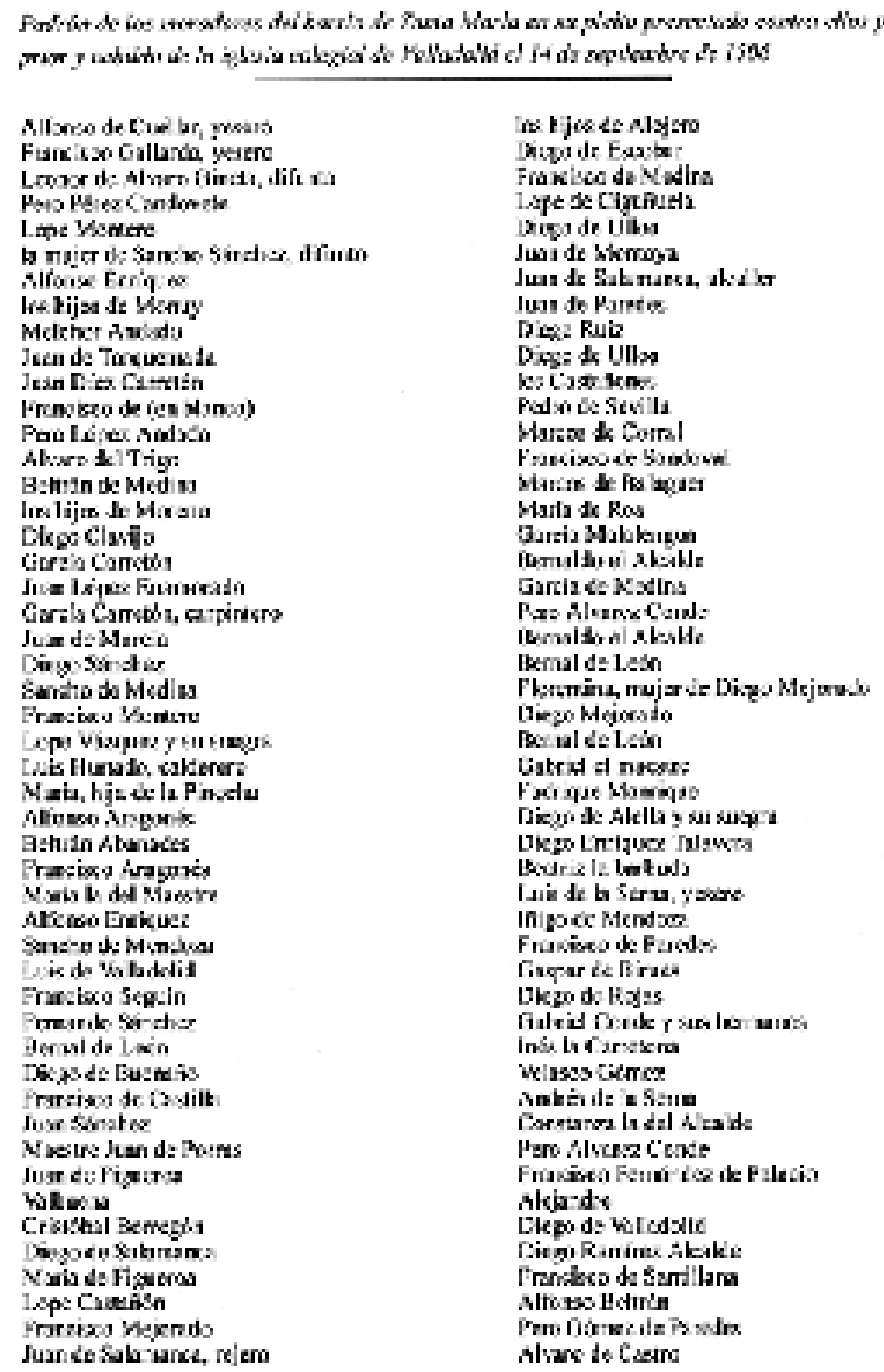




\begin{tabular}{|c|c|}
\hline Alforss PArex ce Viver: & is C. 4 ill.ja \\
\hline sina de Poutills & is muje se Hmrkco de bi lalp m:k \\
\hline 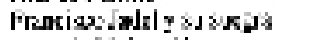 & Carriscarce:in \\
\hline hnsiv adtatib & Fodro de Cern tl sicjs \\
\hline Istilits Pubisis & Cacoric da Ciguruits \\
\hline N:ace da Firen & 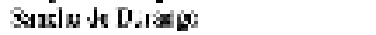 \\
\hline Lix so tamia & 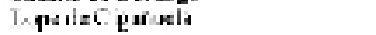 \\
\hline Pero sterimo curpinass & Di:ent: His:ain \\
\hline Confara la del Alezb: & Periloxes: Son Mrrth \\
\hline disgo is ispaex & Gincin Ecabex:s \\
\hline 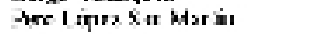 & arzele la Rdz \\
\hline Fruiseyfilutis & Jan delz Raz \\
\hline Just Mrlpalils & Jan da burzos \\
\hline ?oufigstix:2 & lisev ol, kiltiduld \\
\hline Frasciss de vurc a & 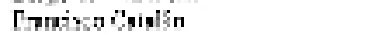 \\
\hline varid la Photia & Rotu dinare Cuml: \\
\hline Dwipo tenalas. & 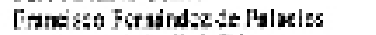 \\
\hline Ter bua fe Muris & Qistacos $d=$ walls jold \\
\hline Hodro de Cerm. el sing & 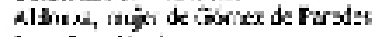 \\
\hline Garcic Canutóa & Inu 'ni: Niail \\
\hline Tandioco Eitmo & F1atje Mcnา:us \\
\hline Erricus fisms, su batraso & Pamedace Kables \\
\hline Rugitorter. & Sure te Malparifa \\
\hline 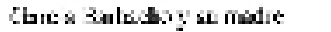 & Anborio Cambor \\
\hline Henal: truata" & DeTd da Lin \\
\hline Pandeco Perandezce Palyeies & กiz, '̌ej suala \\
\hline :Aarocs d: Corats? & 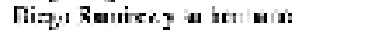 \\
\hline Pran:bce nutads & 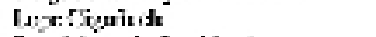 \\
\hline Diagoclavio & Fars Lyp:2 d: Sca banin \\
\hline Its tjue dv & Jocide Saakanin \\
\hline Petrita-ib to & Giaciad aballe \\
\hline 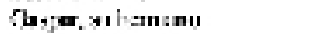 & lavete Treogisomadio \\
\hline londzonmen & Ia Larciva \\
\hline A.ro ic de Cas.tio & hlousotestoniny \\
\hline difousoce hatousicisar & Cirgo de Da:ro to \\
\hline Gemardoel reasess & Fotis avido \\
\hline Jundo Ionsoidke & Dembl d: L:kin \\
\hline Parte is Mugiasis & I:ig a alcolde \\
\hline Ferro bia: bitus & Catalea la focoa \\
\hline Psomenesid Ahalde: & Pog N:ul \\
\hline Ara dalCralila & denis Hairg:er \\
\hline Jaet 6 \& Paloks & Prdeo ce Ritors \\
\hline los hjos te kun del Caall: & Dieg: Daizs. \\
\hline Ereziece hiceds & Garia dilisols. \\
\hline Pryiux & Just \& Santdait in \\
\hline bohelita Dabarin: & rixazia é Alalds \\
\hline Gincia Ratariby alract & lins: $1 \mathrm{~g}$ lin: \\
\hline $\operatorname{lx}+\mathrm{F}+\mid \mathrm{n} n$ & Ispetizulas: \\
\hline
\end{tabular}




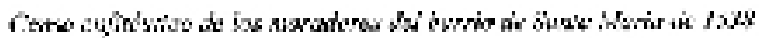

\begin{tabular}{|c|c|}
\hline Tirulal & 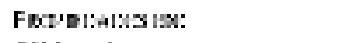 \\
\hline 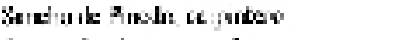 & Crothesto \\
\hline 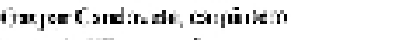 & 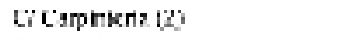 \\
\hline Afodatalow corpirser: & CrCarpievene. \\
\hline lared:Narcis carsiatro & we:ni-her: \\
\hline 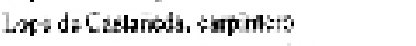 & crcamiser: \\
\hline 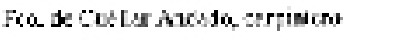 & CACoridtic \\
\hline 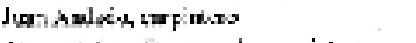 & Worailer's \\
\hline 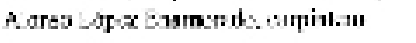 & ClCu siats y cicuners \\
\hline Ja, zar Andsu (mpans? & recrsindeisycicom lla \\
\hline 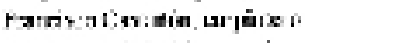 & clcudaer's \\
\hline 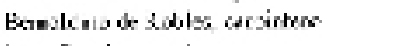 & $C$ Carpinsta $(2)$ \\
\hline 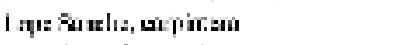 & ClCarpinels \\
\hline Laper miatio, aspiras & Crcupinsels \\
\hline 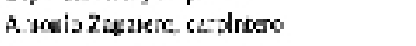 & 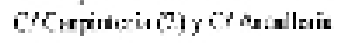 \\
\hline futrie d: Wirza sarfirtess & crcopenesis \\
\hline 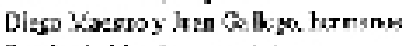 & Crapresis \\
\hline Suf ith de Mitisos. expernes & 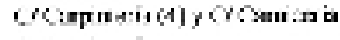 \\
\hline 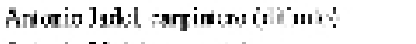 & Chopitais \\
\hline 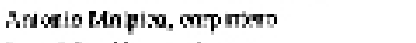 & Comapiestit \\
\hline Inx Virejistapings & Clcarpurafis \\
\hline 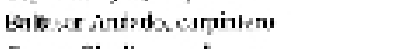 & Crcantitai \\
\hline fiste Clavia cartiners & C'Compriti, \\
\hline 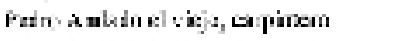 & cicampera \\
\hline Frurlece sudsdo cu häm surpinas & dComp.zin \\
\hline Trkasa de Cizuĩusla, caphor & Catamn:ars \\
\hline 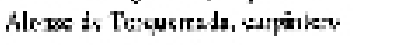 & 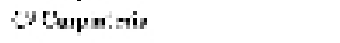 \\
\hline Jech Smons, ला:p n:.nv & cytimisum \\
\hline 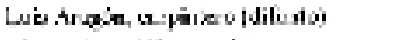 & Qtamiaris \\
\hline flose to sy bn surpirim: & ClGartar:aia \\
\hline 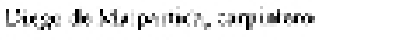 & ClOarinteria \\
\hline 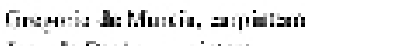 & Elcamin:an \\
\hline 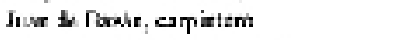 & Cicapirtaric \\
\hline 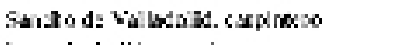 & ¿camorts \\
\hline Lep: ds Ayllth cerpinsts & vcomminto \\
\hline 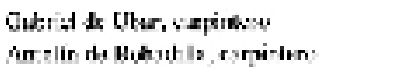 & 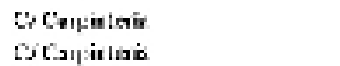 \\
\hline Abeso Picz cerpintave & Crarirturis y cicarillo \\
\hline 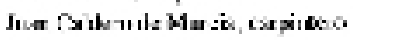 & Cicansirterie. \\
\hline
\end{tabular}




\begin{tabular}{|c|c|}
\hline Citpiaib d: Ciauitedc, sapn niso & Cidriatias CrCamikera \\
\hline 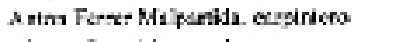 & Corpitatia \\
\hline Abma Cartsin, angittens & civerintara \\
\hline 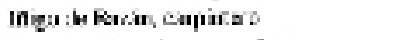 & Cicurpersion \\
\hline 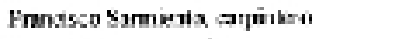 & cicapinerh \\
\hline J.end: Retina cupn $k \mathrm{ro}$ & DVMercads \\
\hline Ansetia da Ritero, tarpiatero & C'Ratini \\
\hline Fiarsced:Xaluarics, tareirico & CiCmiäı \\
\hline 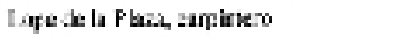 & WComin \\
\hline Biarin, Lipiudas & "berio ted corr la" \\
\hline 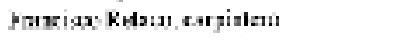 & C: Kercato \\
\hline Aigendro Sturien: a ball: & C) Capir.ats \\
\hline Lais Castakn alaallat !t funn! & C'Cupirais \\
\hline Gócsalo del Telza, skalix & 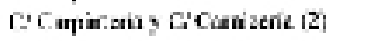 \\
\hline Outia Aksh= al:aller & 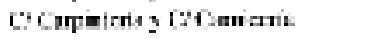 \\
\hline 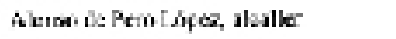 & C: Camportas) \\
\hline Evikne Telb:c, tialla & C'Camberb (2) \\
\hline Cratosal comardec, strallar & C'Camberis \\
\hline Don Juar. alkall:t & C.Canive i i $(2 \mathrm{~J}$ \\
\hline Funisso Chuphe:a alaslkr & Conikeis \\
\hline Akja Renires alalk: & Cicamiogia \\
\hline [jicen fuarines, abolk: (difuate) & C'Camierta ( $/$ ) \\
\hline LuaConisure e: Illkn, alala & C'Senketis \\
\hline Brseris Akskit: & Cicentio:is \\
\hline Dikgo do Cienzros, alakk & C'A:l ulruji \\
\hline .wan Moertev, aleslin & Cicurrín \\
\hline Gispar é Palocies, ckeller & CiCamikstia \\
\hline Logede Rojis, shalk & Cicarirkring cicamiboris \\
\hline Jiegu Murarr, dedlar & cicenkeris \\
\hline Ahure de Gsmeids, ukalst & cievintax \\
\hline 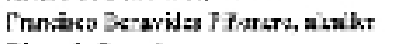 & Wulcointerio \\
\hline Riegn da Segevia yos:m & OVhrpistis \\
\hline Gispar in kiminow yeerm & Cinzpirbria \\
\hline 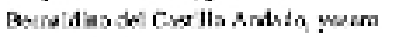 & 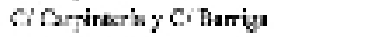 \\
\hline Lopere Resillo, resso & GCopintor \\
\hline 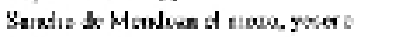 & Quention \\
\hline Alenes de Konsaragus. $\gamma$ sere & LYLeipuratio \\
\hline 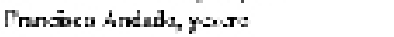 & LYCherasts: \\
\hline Franciven de Ribirs, jeicro & C: Bartigh \\
\hline Prove A-dids d wam, espurles & C'Carpiratia $(z)$ \\
\hline 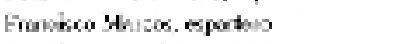 & 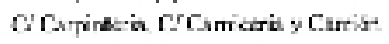 \\
\hline 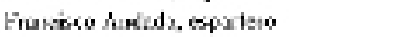 & QCntpinatis \\
\hline
\end{tabular}



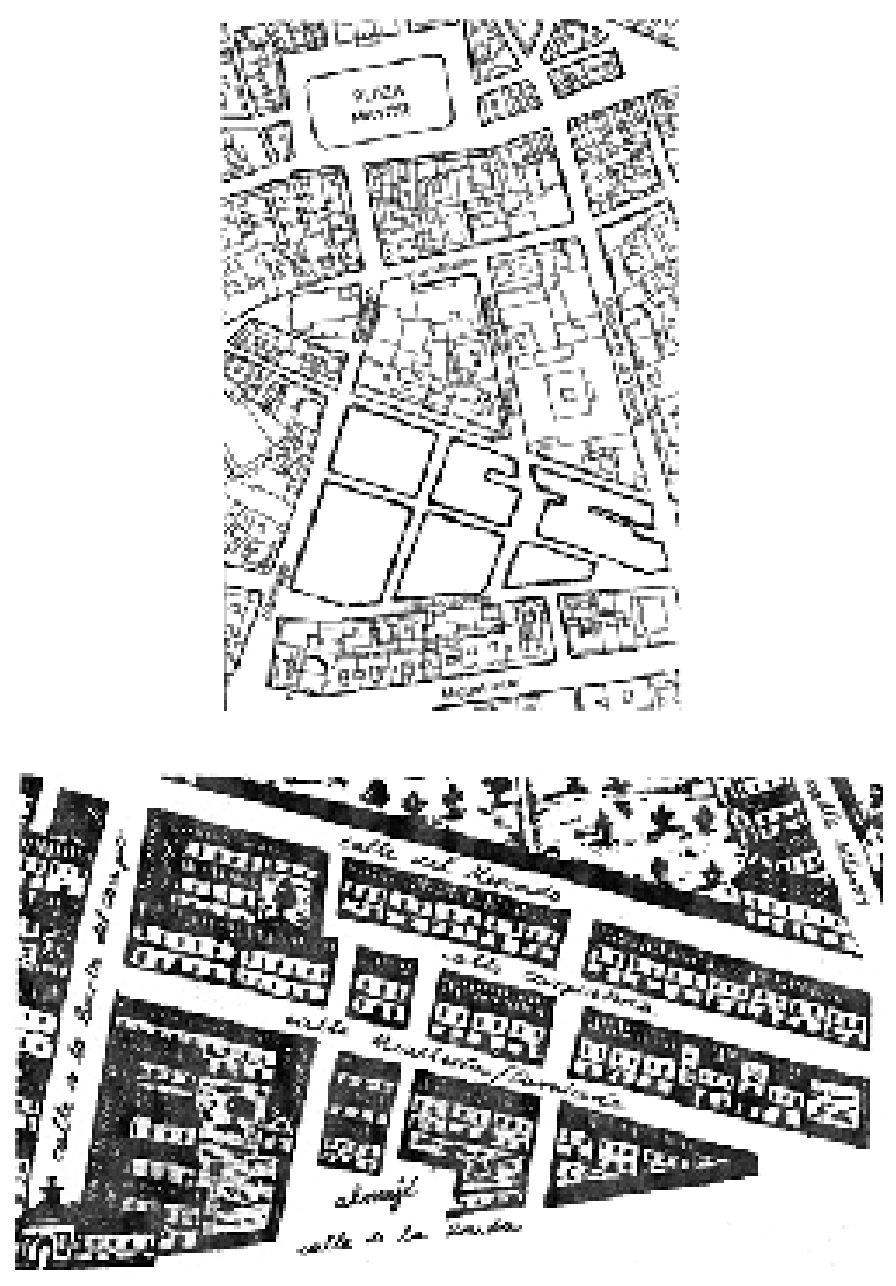

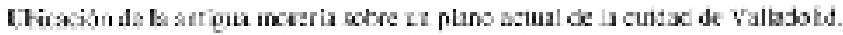

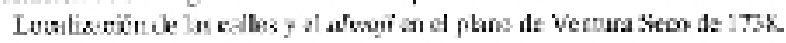

